\title{
On the Ones Who Hear the Whistle: Towards an Analytical Framework for Analysing Complaint Recipients
}

\author{
Selina Rathke ${ }^{1}$
}

\begin{abstract}
Tax avoidance, fraud, endangerment of public safety - criminal offences that would often remain hidden without whistleblowers. Although whistleblowing is a common research subject (e.g. Brown, 2008; Culiberg \& Mihelic, 2017), few studies systematically focus on the recipients of whistleblowers' reports. This lack of attention is striking in light of the decisive role of complaint recipients in the whistleblowing process (e.g. Lewis, Brown, \& Moberly, 2014; Read \& Rama, 2003). Often, it depends on the recipient's response, whether the process comes to a standstill and injustice prevails, or whether corrective action is initiated. Drawing on the scant existing literature, this study develops and applies a comparative framework which allows for a comprehensive analysis of the role of whistleblowing complaint recipients. Findings confirm the framework's utility to assess recipients, their responses and responsibilities. Hence, this study paves the way for the application of a novel analytical focus within whistleblowing research.
\end{abstract}

\section{Introduction}

Tax avoidance, fraud, endangerment of public health - these are only three of many organizational wrongdoings which have come to light in Europe over the past years. This dramatically illustrates the increased need for greater transparency on organizations' activities. When organizations are not sufficiently transparent on their own initiative, the wider public often has to rely on insider information in order to be able to uncover wrongful behaviour. Here, so-called whistleblowers and the processes they trigger can be decisive. As has been argued:

\footnotetext{
Whistleblowing is now established as one of the most important processes - if not the single most important process - by which governments and corporations are kept accountable (Lewis, Brown, \& Moberly, 2014, p. 1).
}

By now, there is a large amount of literature analysing whistleblowing cases (e.g. Brown, 2008; Callahan \& Dworkin, 1994; Culiberg \& Mihelic, 2017; Dworkin \& Baucus, 1998; Mesmer-Magnus \& Viswesvaran, 2005). The whistleblower is crucial for observing and reporting a wrongdoing. The recipient ${ }^{2}$ of this report is, however, similarly vital. His response can determine the overall direction and consequently outcome of the whistleblowing process. Often, the initial recipient decides whether the complaint is ignored or acted upon (e.g. Mazerolle \& Brown, 2008; Mesmer-Magnus \& Viswesvaran, 2005; Moberly, 2014). Despite their importance, so far only few whistleblowing studies focus explicitly on complaint recipients (e.g. Lewis et al., 2014; Read \& Rama, 2003).

\footnotetext{
${ }^{1}$ Selina Rathke received a bachelor of arts degree in European Studies at Maastricht University in 2018. At the time of publication of this volume, she works as an intern at a CSR and sustainability consultancy in Hamburg. Contact: selina.rathke@web.de

2 The 'recipient' can be both male or female. For reasons of readability, this study uses masculine pronouns when mentioning the 'recipient'. However, all information applies equally to male and female recipients.
} 
In order to develop a more comprehensive and deeper understanding of the whistleblowing process, however, light needs to be shed also on these actors. To what extent are complaint recipients different or similar? How do their responses and responsibilities in the overall whistleblowing process diverge? How can differences be explained? In order to address these questions, this study develops and tests a first comprehensive analytical framework which allows for a detailed analysis and comparison of complaint recipients. Through this, it contributes to the academic debate in several ways: First, it answers calls for further research by offering a systematic approach towards analysing whistleblowing with an exclusive focus on the recipient.

Second, by applying and testing the framework on real whistleblowing cases from Germany, it provides initial insights on potential relations between different elements of the framework. Findings suggest that both the wrongdoing and the proximity or distance between wrongdoer and recipient are decisive for the initial recipient and his responses. Moreover, results illustrate the important role of subsequent recipients. Such insights on recipients and their impact within the whistleblowing process may not only inform the academic debate but also future whistleblowers, future recipients or policy makers (e.g. Miceli, Near, \& Dworkin, 2009; Olsen, 2014; Vandekerckhove \& James, 2013). Consequently, findings may also benefit the wider society.

Third, this study adds to existing literature by analysing only real and not hypothetical whistleblowing cases from a European country. This is of value since existing research predominantly focusses on American or Australian cases (Miceli et al., 2009, p. 381). The remainder of this study is structured as follows. The first chapter briefly contextualizes whistleblowing within the broader topic of transparency. The second introduces the developed framework and its comparative elements. Third, the for the application of the framework selected cases and data are presented. The framework is applied to selected cases in the fourth chapter. The last chapter discusses findings and implications for the framework's utility and outlines suggestions for further research. This study concludes by summarizing its main findings and contribution.

\section{On Transparency and Whistleblowing}

The following briefly defines relevant terms for understanding the whistleblowing process and outlines how whistleblowing is related to the wider topic of transparency. Subsequently, this chapter takes stock of what is known about complaint recipients and stresses the need for further research.

\subsection{Whistleblowing and Transparency}

Whistleblowing has been prominently defined by Near and Miceli (1985) as "the disclosure by organization members (former or current) of illegal or illegitimate practices under the control of their employer to persons or organizations that may be able to effect action" (p. 4). Following this, it becomes evident that the whistleblowing process involves at least two different actors. First, the whistleblower who discloses and reports a wrongdoing. Usually, this person is an employee and hence internal to the organization in which the wrongdoing occurs. However, the whistleblower can also be external (TI, 2013, p. 5).

Once the whistleblower reports, a second actor becomes part of the process: the complaint recipient. A recipient is usually characterized by having the ability to correct or terminate the wrongdoing (King, 1997; Near \& Miceli, 1985). He can be internal, such as a manager, internal audit officer or human resource staff member, or external, such as an employee of an external agency (e.g. Donkin, Smith \& 
Brown, 2008; Latimer \& Brown, 2008; Near \& Miceli, 2016). The effectiveness of whistleblowing arguably depends on the extent to which the wrongdoing has been terminated in the end (Near \& Miceli, 1995).

Yet, how is whistleblowing related to the notion of transparency? Transparency is a highly complex and dynamic concept which can be approached and defined from many different angles. As highlighted by Hansen, Christensen and Flyverbom (2015), transparency in the social sciences refers to "objects or activities made visible or legible" (p. 118). Heald (2006) moreover defines transparency in four directions: transparency outwards, inwards, upwards or downwards. The latter approach is particularly relevant with respect to whistleblowing. Downwards transparency describes situations in which "the 'ruled' can observe the conduct, behaviour and/or 'results' of their 'rulers'" (Heald, 2006, p. 27). Following this, whistleblowing may be interpreted as a situation in which the 'ruled' within or outside of an organization observe the wrongful behaviour of their superiors or colleagues. Consequently, through identifying and reporting misconduct, whistleblowers may create, maintain or advance transparency both within public and private organizations (e.g. Latimer \& Brown, 2008; Lewis et al., 2014; Olsen, 2014).

Increased transparency on organizations' activities is closely related to increased accountability (e.g. Hansen et al., 2015; Heald, 2006; Vandekerckhove, 2006). More precisely, one may argue that through their disclosures, whistleblowers enable the wider society to hold organizations accountable to inspection and evaluation (e.g. Lewis et al., 2014; Vandekerckhove, 2009). While the process of whistleblowing may increase transparency on organizations, the respective organizations themselves are, nonetheless, often not transparent in how they manage the whistleblowing situation (Brown, 2008, p. 22). Moreover, there is often a lack of transparency on the complaint recipients involved which this study aims to counter through application of its proposed framework. Besides the rather positive aspects inherent to it, whistleblowing can also have negative consequences for both the whistleblower and the organization in which the wrongdoing occurred. The former often experiences retaliation whereas the latter may encounter reputation damages or additional costs associated with investigations or legal obligations (e.g. Dworkin \& Baucus, 1998; Miceli, Near, Rehg, \& Van Scotter, 2012).

\subsection{Whistleblowing Research and Complaint Recipients}

As becomes apparent, whistleblowing is a highly relevant and sensitive societal issue. Despite the variety of existing whistleblowing literature, many scholars critique the predominance of studies which focus exclusively on the whistleblower and thereby neglect the recipient's perspective (e.g. Lewis et al., 2014; Read \& Rama, 2003; Vandekerckhove, Brown, \& Tsahuridu, 2014). Limiting ourselves to the relatively scant research that does focus on the recipient, we can point to Annakin (2011) who discusses whistleblowing in Australia and pays attention to one type of complaint recipients, namely public accountability agencies. Other scholars have assessed recipients as part of analysing the overall whistleblowing process (e.g. Andrade, 2015), or have identified under which circumstances whistleblowers choose certain recipients (e.g. Bosua, Milton, Dreyfus, \& Ledermann, 2014; Callahan \& Dworkin, 1994; Donkin et al., 2008). Some academics refer to recipients as whistleblowers, suggesting that recipients become whistleblowers once they receive the report of a wrongdoing and then have to act upon it (e.g. Ponemon, 1994; Vandekerckhove et al., 2014).

Despite this literature, it seems that to date no study has analysed and compared complaint recipients in an exclusive manner. Consequently, it becomes a new priority to systematically and comprehensively analyse recipients within different whistleblowing cases. Thus, this study contributes to 
the academic debate by developing an analytical framework against which recipients, their roles as well as their responses can be assessed empirically. The next chapter introduces the developed framework.

\section{Complaint Recipients - Towards an Analytical Framework}

The first section of this chapter briefly outlines how the framework was developed. The second explains the basic frame, which builds upon different stages of the whistleblowing process. The third section then elaborates on the different elements which form the substance of the framework. Here, linkages between different elements are illustrated as well as the elements' particular relevance for analysing the complaint recipient.

\subsection{Developing a Framework}

The methodology applied for developing the framework follows the wider approach of qualitative metasynthesis research (Hoon, 2013). First, existing literature was reviewed in order to reconstruct the stages of the whistleblowing process. Previously identified stages were contrasted with stages of real-life whistleblowing cases to ensure an as complete as possible reconstruction. Next, whistleblowing literature was reviewed which discussed various elements inherent to the different stages. This served the purpose of obtaining an overview of elements and their potential relation with each other and within the process. Following, a selection was made of elements particularly relevant with respect to complaint recipients. Last, selected elements were grouped under the respective whistleblowing stages and thus integrated into a comprehensive framework. For a graphical presentation of the framework see Figure 1.

\subsection{Basic Frame: Stages of the Whistleblowing Process}

When describing the whistleblowing process, scholars tend to differ in the number of stages they identify and what they consider essential in these stages. However, the process itself always follows a similar pattern. From a whistleblower's perspective, Miceli and Near (1992) describe a five-stages-process. The first stage includes the initial triggering event which is followed by pre-whistleblowing actions. In stage three, the actual whistleblowing occurs, followed by responses of others. The final stage covers "the whistle-blower's assessment of organizational reactions" (Miceli \& Near, 1992, p. 55).

In a study for a British whistleblowing advice line, Vandekerckhove and James (2013) structure the phases as follows. First, a wrongdoing is perceived and a concern raised. Then, management and colleagues respond to the whistleblower, followed by the whistleblower calling the advice line. Afterwards, consequences for the whistleblower and the wrongdoing become apparent which moreover influence the final outcome of the whistleblowing process. Taking these categorizations into account, following four stages constitute the basic frame of the developed framework: The first stage, perception of the wrongdoing, includes the observation of the wrongdoing by an individual, either internal or external to the given organization. In this stage, two actors are involved: the observing individual and the body who engages in or causes the wrongdoing.

\footnotetext{
Marble

4 Research

Papers
} 


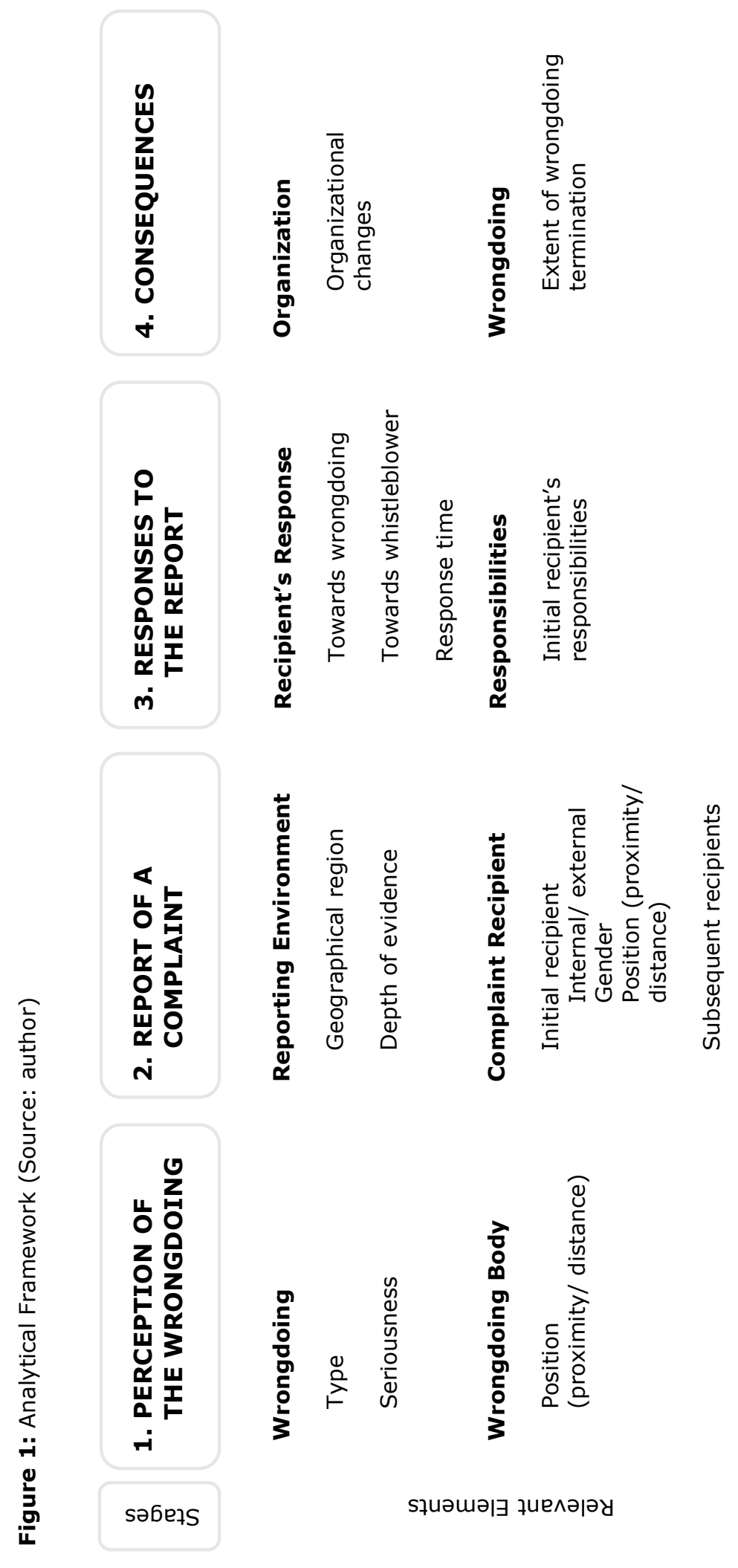


In the second stage, report of a complaint, the individual becomes a whistleblower by reporting his or her observations. Hence, the recipient of the report becomes part of the process. In the third stage, responses to a report, initial and subsequent recipients respond to the reported wrongdoing and the whistleblower. The fourth and last stage, consequences, allows for an assessment of the different corrective actions initiated through the recipients as well as consequences for the wrongdoing and the organization in which it occurred.

\subsection{Substance: Elements for Comparison}

As illustrated in Figure 1, the most relevant aspects in relation to the complaint recipient have been identified for each stage. This leads to a meaningful arrangement of relevant elements, adding structure and clarity to the framework.

\subsubsection{Perception of the Wrongdoing}

Concerning the wrongdoing observed, two elements need to be assessed: its type and its seriousness. Wrongdoings may induce safety problems, ethical or environmental concerns and can cause physical, economic or psychological harm (e.g. Dworkin \& Baucus, 1998; Rehg, Miceli, Near, \& Van Scotter, 2008; Vandekerckhove \& James, 2013). As argued by Smith and Brown (2008), the type of wrongdoing has a significant impact on the outcome of the whistleblowing process. Since this outcome is arguably dependent on the recipients' responses, it seems particularly relevant to assess and compare the type of wrongdoing in different whistleblowing cases in relation to different recipients.

Similarly, the relation between seriousness of the wrongdoing and recipient may be decisive. Dworkin and Baucus (1998) defined very serious wrongdoings as those involving physical harm such as "endangering public or workers' safety or health" (p. 1285). Less serious wrongdoings are those causing economic harm through, for instance, loss or damage of property. Wrongdoings evoking psychological harm are categorized as the least serious (Dworkin \& Baucus, 1998). Despite this clear designation, it remains questionable whether economic harms can generally be categorized as more serious than psychological harms. In order to relativize this, seriousness can be assessed also based on the number of persons affected by the wrongdoing (Rehg et al., 2008).

Concerning the wrongdoing body, the most relevant element to assess and compare is its position. This element is particularly important vis-à-vis the position of the initial recipient. Establishing both actors' positions allows for an assessment of their relative proximity or distance. The proximity or distance may have an influence on the initial recipient's response and in turn may impact who the initial recipient is. Summing up, all three elements from the first stage may be decisive for who the complaint recipient is and how he responds to the whistleblowing situation.

\subsubsection{Report of a Complaint}

The second stage is characterized by the reporting of an observed wrongdoing. Here, reporting environment and recipient of the complaint are important. Two elements need to be assessed with respect to the reporting environment: first, the geographical region in which the concern was raised, and second, the depth of evidence that was provided to substantiate the report. As proposed by Messer and Shriver (2009, p. 665), organizational responses to whistleblower's reports may differ depending on the geographical region. Developing Messer and Shriver's (2009) assertion further, one may expect any recipients' responses to differ across different regions. Moreover, it has been argued that recipients vary 
across regions due to different regional laws and statutes prescribing who the recipient should be (Dworkin \& Baucus, 1998). Further, there might be North-South or East-West regional differences. Nevertheless, any such pattern still needs exploration before clear assumptions can be put forward. Therefore, including the region-element may provide insights on this element's potential influence on the wider whistleblowing process.

The depth-of-evidence element refers to the extent to which the observer of a wrongdoing can substantiate his or her report to the recipient. Based on real case examples, one may assess this by analysing in how far whistleblowers relied on either physical evidence or unrecorded oral or visual memories. Miceli and Near (2002, p. 474) found that most recipients judge reports to be not sufficiently founded. Smith and Brown's (2008, p. 119) findings moreover indicated that if a report is rather unsubstantiated, recipients' responses tend to be negative. Miceli et al. (2012, p. 943), on the contrary, suggest that recipients encourage the reporting of hints which are based on little evidence or mere suspicions. Consequently, an assessment and comparison of this evidence-element in relation to recipients' responses seems particularly interesting.

With respect to the complaint recipient, two elements are relevant to assess. The first serves the identification of the initial recipient. More precisely, this element involves an assessment of whether the recipient is internal or external, which gender the person has and how close or distanced the recipient is relative to the wrongdoer. Many scholars argue that most initial recipients are internal (e.g. Annakin, 2011; Ponemon, 1994; Vandekerckhove \& James, 2013; Vandekerckhove et al., 2014). Assessing this among more cases and especially in Europe, is thus relevant for evaluating whether this common assumption really holds. Moreover, gender is argued to be of importance within the whistleblowing process, especially from the whistleblower's perspective (e.g. Bjørkelo, Einarsen, \& Matthiesen, 2010; Rehg et al., 2008; Wortley, Cassematis, \& Donkin, 2008). Focussing on the initial recipient's gender may provide valuable insights as to which role gender may play in determining the recipient's response. Next, establishing the initial recipient's position is important for assessing the proximity or distance between recipient and wrongdoer. This in turn may influence not only who the initial recipient is but also how he responds, as explained above.

The second element serves the identification and assessment of involved subsequent recipients. Vandekerckhove et al. (2014) stipulate that whistleblowing often involves a chain of speakers and hearers. The first speaker, the whistleblower, turns to the first hearer, the recipient, who in turn may also become a speaker when forwarding the received report to another person. This person is then another hearer who might become another speaker and so forth. Moreover, it is particularly interesting to assess the sequence of recipients within such chains: were reports made to only internal, external or first internal and then external recipients (Donkin, Smith, \& Brown, 2008)? As has been argued, in cases where the initial recipient is internal, also subsequent recipients tend to be internal (e.g. Annakin, 2011; Vandekerckhove \& James, 2013). All the more it is relevant to compare this element across different cases in order to identify such patterns within chains of recipients.

Moreover, reconstructing this chain helps to assess at which point and by whom direct corrective action was initiated, an aspect relevant for the following stage. To sum up, whereas the region-element might explain who the initial recipient is, the remaining elements of the second stage serve a better comparison of who the recipients are and how they respond under which circumstances. 


\subsubsection{Responses to the Report}

In the third stage, the focus lies on the responses of recipients and the initial recipient's responsibilities. Recipients may respond to the actual wrongdoing and to the whistleblower (e.g. Vandekerckhove et al., 2014, p. 300). Not to forget, they may not respond at all (Vandekerckhove \& James, 2013). The first element concerns the recipients' responses towards the reported wrongdoing. A positive response would be, for example, to immediately initiate the carrying out of investigations into the reported wrongdoing (Miceli et al., 2009, p. 379; Smith \& Brown, 2008, p. 120). A negative response would be to ignore the reported wrongdoing and to thereby approve its continuation.

The second element identifies the recipients' responses towards the whistleblower. Here, a positive response may be to support or protect the whistleblower. A negative response may be to ignore the whistleblower or to implement retaliation measures, such as giving unfavourable job evaluations, exerting pressure, or harassing the whistleblower (e.g. Loyens \& Maelsschalck, 2014, p. 165; Rehg et al., 2008, p. 230; Smith \& Brown, 2008, p. 128). Assessing different recipients' responses may not only shed light on different response patterns but may also help to establish who was when supportive, eventually enabling action towards terminating the wrongdoing.

The third element concerns the recipients' response time. Whether the report was followed by an immediate or delayed response may be decisive for the sequence of further steps taken and hence for the overall whistleblowing process. In the best case, a recipient should respond immediately with corrective actions (Miceli et al., 2009, p. 379). The quickness of a response may depend on the type of response itself as well as on whether the recipient is internal and external. Dworkin and Baucus (1998) argued that retaliatory firing is a more immediate response if the report was made internally. Moreover, timing and type of response conjoin with the evidence-element from stage two: whether and in which rapidity any corrective action is taken arguably depends on how sufficiently the report is founded (Miceli et al., 2009, p. 387).

With the last element, the initial recipient's role-prescribed responsibilities are assessed. After having analysed the elements from stage two, it is by now clear who the initial recipient is and how he responded. Hence, one can now focus on this recipient's particular responsibilities to react to a whistleblower's report in a certain manner. Comparing this across different cases may provide insights on whether recipients have particular role-prescribed responsibilities and whether they are aware of and follow them. All in all, analysing the four elements from stage three enables a thorough description and comparison of how and why recipients' responses may differ.

\subsubsection{Consequences}

The fourth and last stage concentrates on the broader consequences of the whistleblowing process. Here, elements focus on consequences for the organization as well as for the wrongdoing. The first element assesses whether the concerned organization underwent any organizational changes such as procedural or management changes (e.g. Smith \& Brown, 2008, p. 116).

The second element deals with the extent to which the wrongdoing was terminated. It should be noted that this element might be difficult to assess. Nevertheless, it is possible to investigate in how far the wrongdoer was constrained, consequently allowing to evaluate the likelihood of the wrongdoing recurring. Especially in cases which are not too recent, one may retrieve indications as to whether the wrongdoing was continued or observed again. Assessing these two elements in relation to other elements from previous stages can give valuable insights on potential relations between recipients, their responses 
and the overall outcome and consequently effectiveness of the whistleblowing process. After having presented the framework, this study moves on to apply the framework on a selection of German whistleblowing cases. Before doing so, the next chapter briefly explains how respective cases and data were selected.

\section{A Note on Cases and Sources}

\subsection{Selection of Cases}

Since this study's main purpose lies in the development of the framework, the following analysis is limited to two cases. In order to, nonetheless, test the framework in a meaningful way, two cases were selected which are different in time period and sector in which the wrongdoing appeared. The first case, hereafter referred to as the Alte Apotheke (old pharmacy) case, is a recent case from 2016. Here, the wrongdoing occurred within a private sector business. The second case, hereafter referred to as the Finanzamt (tax office) case, is from 2001 and the wrongdoing occurred within a public sector institution. Being able to apply the framework to all cases no matter how different, will greatly increase its overall value.

Further, both selected cases occurred in Germany. Whereas a majority of studies analyse whistleblowing cases from America or Australia (Miceli et al., 2009, p. 381), European countries are only rarely subject to whistleblowing research (e.g. Hassink, De Vris, \& Bollen, 2007; Lewis, 2006; Pittroff, 2011). By focussing exclusively on cases from a European country, this study consequently aims to enrichen to the academic debate. Germany has, so far, no designated overarching rules or legislation on how to deal with whistleblowing and whistleblowers' reports precisely (e.g. AWG, 2010; Frank, 2018; Strack, 2008). As a result, public and private organizations tend to install individual whistleblowing systems or customized policies (Frank, 2018). Consequently, approaches can differ across the Länder and industries. With this lack of clear and uniform rules, it seems particularly interesting to focus on German whistleblowing cases and on the involved recipients of German whistleblowers' reports.

\subsection{Selection of Sources}

Gathering sufficient and reliable information on whistleblowing cases for research purposes can become quite challenging, notably since cases often involve sensitive issues (Keenan \& McLain, 1992). Additionally, no academic or secondary literature has focussed on the for this study selected cases. Hence, this analysis relies mainly on newspaper articles and articles from an investigative website. Newspaper articles usually serve as a primary source, providing direct information on a certain issue or event (McCulloch, 2004). However, this source conveys information in a quick and sometimes simplified form and hence, should be treated with caution. In light of the newspaper's political orientations and target groups, articles may not present information in a truly comprehensive and balanced manner. In order to overcome these potential bias or insufficiencies, only articles from newspapers renowned for their investigative and thorough journalism were consulted. Moreover, articles were "cross-check[ed]" (Storey, 1999, p. 44) and put into context with information provided on the website presented in the following. 
The AnsTageslicht website ${ }^{3}$ has been created by media and whistleblowing researcher Prof. Dr. Johannes Ludwig. On this website, he publishes extensively researched summaries, chronologies, and in part also relevant primary sources of German whistleblowing cases. Respective articles are usually written in collaboration with students of the Hamburg University of Applied Sciences. While not presented in an academic format, the articles are well researched and always acknowledge when information discrepancies exist. The next chapter applies the developed framework on the selected cases.

\section{German Whistleblowing Recipients}

\subsection{Alte Apotheke Case, 2016}

\subsubsection{Perception of the Wrongdoing \& Report of a Complaint}

In the Alte Apotheke case the wrongdoing caused safety problems and endangered public health. The pharmacist, owning a cyto-laboratory for preparing patients' individual cancer medicines, secretly dosed these medicines too low or did not include any active substance at all (Hesse, 2017). Thereby, he not only broke pharmaceutical rules and principles but also endangered the life of patients. In line with Dworkin and Baucus' (1998) classification, this wrongdoing, causing physical harm, is very serious. The wrongdoing was not impeded for at least three years and around 3700 people are affected by it, reinforcing the wrongdoing's seriousness (Hesse, 2017; Spilcker, 2017). The wrongdoing body, pharmacist and owner of the pharmacy, has a high-status position within the organization.

The wrongdoing was reported in the city of Bottrop in North Rhine-Westphalia in western Germany. The depth of evidence provided to substantiate the report was very profound. Over months, the whistleblower reviewed calculations showing that much less medicine had been actually purchased than prescribed by doctors (Schenck, Schröm, \& Konrad, 2017). Consequently, sold medication could not contain much, if any, active substances. Moreover, an unused infusion bag served as direct evidence (Schenck et al., 2017).

The report's initial recipient was the whistleblower's lawyer (Harrich, 2017). Not being part of the organization, this recipient is an external and moreover male recipient. As concerns the proximity between him and the wrongdoer, it can be argued that both actors are rather distanced, not seeming to share any closer ties or connections. Moreover, subsequent actors received the report. First, the lawyer transferred the report as a complaint to the public prosecutor's office for economic crime in Bochum, hence to another external recipient (Mayr, 2017). From there, the report was forwarded to the public prosecutor's office in Essen which in turn commissioned also the police.

\subsubsection{Responses to the Report \& Consequences}

While the initial recipient did not take any direct corrective action in response to the wrongdoing, he nevertheless responded in a supportive manner by filing the complaint to the public prosecutor's office (Mayr, 2017). Direct subsequent recipients then responded with corrective action targeted at terminating the wrongdoing. The public prosecutor initiated a raid of the pharmacy, arrested the wrongdoer and later filed an indictment against him (e.g. Bensmann et al., 2017; Milk, 2017; Wolfund \& Süselbeck, 2017). The initial recipient responded in a similarly supportive manner to the whistleblower, encouraging him to

${ }^{3}$ http://www.anstageslicht.de/home/

Marble

10 Research

Papers 
make the issue public. Subsequent recipients' responses were arguably less directly addressed towards the whistleblower. Nevertheless, at a later time another external subsequent recipient, the State Labour Court, responded positively towards the whistleblower by attributing him a settlement amount for the instant dismissal which had been initiated by the wrongdoer (Linnhof, 2018). While the initial recipient responded immediately to the whistleblower's report, five months passed between the prosecution receiving and responding to the report (Mayr, 2017). The initial recipient's role-prescribed responsibilities as a lawyer comprise mainly giving independent advice to clients and protecting them from wrong decisions or loss of rights ${ }^{4}$. Based on what is known, the initial recipient did follow these responsibilities. However, it should be noted that these responsibilities do not refer specifically to whistleblowing situations.

In the course of the whistleblowing process, the pharmacy underwent some management changes. The wrongdoer and owner is still under arrest; the new owner is his mother (Schraven, Bensmann, \& Helberg, 2018). Hence, this change is arguably not a very drastic one. A greater change in contrast, lies in the pharmacy no longer having an own cyto-laboratory (Opitz, Kuhrt, \& Lauerer, 2017). Concerning the extent to which the wrongdoing has been terminated, one can argue that the wrongdoing has indeed been stopped. The wrongdoer currently faces ten years imprisonment and will not return to the pharmacy any time soon (Schenck et al., 2017). Moreover, the Health Minister of North-Rhine Westphalia has announced stricter regulations for controlling pharmacies, in order to prevent such wrongdoings from happening again (Frigelj, 2017).

\subsection{Finanzamt Case, 2001}

\subsubsection{Perception of the Wrongdoing \& Report of a Complaint}

The wrongdoing in the Finanzamt case resulted in economic harm and ethical concerns. More precisely, tax investigators concerned with tax evasion through banks were heavily obstructed in their work. An internal regulation, issued by the head of the Frankfurt tax office department $V$, stipulated that an initial suspicion of tax evasion may only be raised in banking cases where "there is a transfer volume of over DM 500,000 [€250,000] or an individual transfer of DM 300,000 [150,000]" (Finanzamt, 2001, p. 3). However, assets are usually divided into small tranches in order to be exempted from tax liabilities. Under the given regulation, all these amounts fell out of the investigations' scope, forcing tax investigators to ignore certain suspicions of tax evasion (Hunfeld, 2008; Ludwig, 2018). This in turn may cause economic harm to Germany's public treasury in the long term.

Following Dworkin and Baucus (1998), this wrongdoing is less but still moderately serious. One might expect that losses to the treasury affect all German citizens at some point (Schmenger, 2018). The fact that the regulation was not revoked for three and a half years affirms its seriousness (Ludwig, 2018). The wrongdoing body is the head of the tax office himself (Finanzamt, 2001; Hunfeld, 2008). Hence, he has a high-status position within the organization. The wrongdoing was reported in Frankfurt am Main, a city in Hesse in western central Germany. The evidence supporting the report was arguably sufficient, since a written copy of the respective regulation and written protest letters and complaints were accessible (Obertreis, 2009). The initial recipient of the report was the head of the tax office himself (Ludwig, 2018). Hence, the initial recipient is internal and moreover male. Since initial recipient and wrongdoer are the same person in this case, the element of distance can be suspended.

\footnotetext{
${ }^{4} \S 1$, BORA (German Professional Code of Conduct for Lawyers)
} 
Furthermore, subsequent recipients got involved. First, another internal recipient, namely the head of the respective department, received the report (Ludwig, 2018; Thieme, 2009). Second, the internal chief financial president took note of the complaint. Later, the Hessian Ministry of Finance was informed (Ludwig, 2018). In this case, the Ministry is also an internal recipient, since it is the overarching authority of all Frankfurt tax offices (Hessisches Ministerium der Finanzen, 2018). A first external recipient who received the complaint was at a later time the public prosecutor responsible for bank cases at the Frankfurt am Main Regional Court (Hunfeld, 2008; Ludwig, 2018). Moreover, external politicians and media found out about the report.

\subsubsection{Responses to the Report \& Consequences}

The initial recipient did not respond to the wrongdoing, but only to the whistleblower as is explained below (Hunfeld, 2008; Obertreis, 2009). The subsequent internal recipient, head of the department, responded in an arguably supportive manner in so far as he criticized the new regulation himself (Hunfeld, 2008; Ludwig, 2018). However, this did not lead to any corrective action since he was transferred to a new workplace upon initiation of the next subsequent recipient, the chief financial president (Ludwig, 2018). Moreover, the Hessian Ministry of Finance did not terminate the wrongdoing and instead emphasized responded that respective investigations should continue to follow the regulation's instructions (Ludwig, 2018). Only later, subsequent external recipients, namely politicians and media took direct corrective action by triggering the dissolution of the tax office.

The initial recipient's response towards the whistleblower was very unsupportive, taking the form of retaliatory measures. First, psychological pressure was exerted and later, disciplinary investigations were initiated against the whistleblower for minor mistakes (Hunfeld, 2008). The retaliation cumulated with a medical examination through which the whistleblower was diagnosed with mental illness and consequently had to retire (Bartsch, 2008; Ludwig, 2018; Thieme, 2009). Internal subsequent recipients did not respond directly towards the whistleblower but also did not prevent retaliation. Only later, external subsequent recipients supported the whistleblower by inter-alia compensating him for the damage caused (Ludwig, 2018; Thieme, 2009).

The initial recipient did not respond to the wrongdoing, but immediately responded to the whistleblower (Ludwig, 2018; Obertreis, 2009). The subsequent recipients' response followed directly and quite timely in the weeks and months after having received the reports (Hunfeld, 2008; Ludwig, 2018). It may be assumed that the initial recipient had, besides his general supervisory and advisory responsibilities as head of the office, no role-prescribed responsibility to respond to the whistleblower's complaint in a certain manner. In some cases, district administration offices install specific anti-corruption officers or internal auditors to whom any person should then forward a complaint report (TI, 2017). However, from the respective tax office's website and its organigram it does not become apparent that such authority had been installed.

In the course of the process, the given organization first underwent staff changes. Most of the tax investigators, including the whistleblower, were eventually relocated or retired (Hunfeld, 2018; Ludwig, 2018; Obertreis, 2009). The decisive change for terminating the wrongdoing was made with the later dissolution and full reconstruction of the tax office (Hunfeld, 2008; Ludwig, 2018). Consequently, it can be argued that the wrongdoing has been indeed terminated for the time being. Moreover, no similar wrongdoings have been reported until now. The following chapter moves on to discuss this analysis' 
findings and to address their wider implications for the advantages and potential limitations of the developed framework.

\section{Discussion}

The first section discusses the main findings and insights gained concerning the initial recipient. The second section then evaluates respective findings on subsequent recipients and recipients' responses. Based on this, the third section discusses the advantages, applicability and potential limitations of the developed framework.

\subsection{Initial Recipient}

Findings from the foregoing analysis suggest that type and seriousness of the wrongdoing seem to affect who the initial recipient is. Both analysed cases included different types of wrongdoings and in both cases the initial recipients differed in terms of being internal or external and in terms of proximity to the wrongdoer. In the Alte Apotheke case, where the wrongdoing was very serious and involved health safety concerns, the first person receiving the report was a lawyer. Hence, the initial recipient was external and had a rather distanced relation to the wrongdoing pharmacist. In the Finanzamt case, where the wrongdoing was less serious, the head of the office received the complaint first. Hence, the initial recipient was internal and at the same time also the wrongdoer himself.

Due to the limited generalizability of findings it remains impossible to claim that who the initial recipient is depends on the type and seriousness of wrongdoing. However, it only seems logical that in cases of severe wrongdoings, a distanced and hence external recipient is consulted, expecting him to have better capacities to assess the given report. This finding is moreover in line with Lewis (2006) who argued that who is contacted as a recipient always depends on "the seriousness and sensitivity of the issues involved" (p. 81).

Moreover, the proximity or distance between the wrongdoer and the initial recipient seems to have an effect on the initial recipient's response. In the Alte Apotheke case, the wrongdoer and initial recipient had a very distanced, if barely any relation to one another. Here, the initial recipient's response was overall positive, triggering action to terminate the wrongdoing and supporting the whistleblower. In the Finanzamt case, on the other hand, wrongdoer and initial recipient were the same person. In this case, the initial recipient did not take any steps towards correcting the wrongdoing and was very unsupportive towards the whistleblower. This may be explained by the initial recipient's level of involvement within the respective organization. If initial recipient and wrongdoer are very closely connected, the recipient can be expected to be very involved within the organization. Consequently, the initial recipient is more likely to be an internal recipient, as in the Finanzamt case. Such dependency of an internal recipient on the wrongdoing organization may then determine the likelihood of any action taken to terminate the wrongdoing (Miceli \& Near, 2002).

Furthermore, findings suggest that initial recipients seldom have role-prescribed responsibilities to respond to whistleblowers' reports in a designated way. Neither the lawyer nor the head of the tax office seemed to have specific whistleblowing responsibilities. However, it also needs to be stressed that it is rather difficult to access respective information on recipients' possible responsibilities. Nevertheless, it may be assumed that sources would have indicated if given recipients had a specific responsibility and 
either did or did not follow it. Again, these findings are limited in their generalizability. In other cases, initial recipients may have specific responsibilities, being for instance internal audit or anti-corruption officers. For these cases, it would be interesting to assess in how far responsibilities were assumed.

\subsection{Subsequent Recipients and Recipients' Responses}

With respect to subsequent recipients, findings seem to support the idea that in most cases there is a chain of either internal or external recipients (Donkin et al., 2008; Vandekerckhove et al., 2014). Whereas in the Alte Apotheke case the initial recipient was external and subsequent recipients also remained to be external, initial and first subsequent recipients in the Finanzamt case were internal. However, in the latter case also external recipients became eventually part of the chain.

Again, it needs to be recalled that it remains difficult to generalize findings. Other non-presented cases may involve only one initial recipient, consequently shortening the whole process. The awareness of these 'fast' whistleblowing cases is, however, limited. Usually, public awareness of whistleblowing cases arises through respective media-coverage. Cases which gain media attention, are, however, often cases which were not solved immediately (e.g. Lewis et al., 2014; Olsen, 2014). Thus, chances are high that cases which are known and consequently more frequently analysed tend to involve a chain of recipients. For a truly balanced picture on this element, further research should thus pay attention to also analysing cases which are less known.

As concerns recipients' responses, not the initial recipient but subsequent and presumably external recipients seem to be the ones eventually taking action to correct or terminate the wrongdoing. In the Alte Apotheke case, it was not before the public prosecutor's office received the report that direct corrective action was taken by initiating a raid of the pharmacy and arresting the wrongdoer. In the Finanzamt case, direct corrective action by dissolving the respective tax office was not taken before politicians and media got involved. These findings support the suggestion that recipients should always be persons "who are not part of the work unit to which the disclosure relates" (Brown, Meyer, Wheeler, \& Zuckerman, 2014, p. 487). Moreover, one may claim that subsequent recipients, rather than initial recipients, thus make an overall greater contribution to the whistleblowing process. Such assumptions need however further empirical assessment. Additionally, the developed framework may need to be refined to include an element assessing also subsequent recipients' role-prescribed responsibilities.

It needs to be noted that it was not possible to derive any patterns with respect to the regionelement. In both analysed cases, the wrongdoing was reported in central western Germany. Moreover, though the two cases occurred in different states, neither of them has particular state law on whistleblowing which could account for any differences. Consequently, this element needs to be further assessed on other cases across different regions. Similarly, no patterns could be established between the initial recipient's gender and other elements of the framework. Both initial recipients were male. Again, further research should analyse other cases in order to assess whether gender really has a decisive role with respect to complaint recipients.

Last, it seems that depth of evidence is not directly related to either recipients' response time or type. One may expect that the more profound the level of evidence, the more immediate and supportive the recipients' response is towards correcting the wrongdoing. However, whereas in both cases the level of evidence was profound and indeed the initial recipient responded immediately, it still took time in both cases until respective corrective action was taken. Again, the generalizability of this finding is very limited 
and hence further research should continue to investigate the impact of the level of evidence. Moreover, response time and type may be influenced by a factor not included in this framework, namely, the recipients' personal attitudes and preferences (e.g. Bjørkelo et al., 2010; Mazerolle \& Brown, 2008; Smith \& Brown, 2008). This study returns to this aspect in the following.

\subsection{Implications for the Framework's Value}

As demonstrated, the application of the framework facilitates an overall systematic analysis of different whistleblowing cases, allowing to shed light particularly on complaint recipients. Its values can be summarized as follows: First, the framework enables a comprehensive reconstruction of whistleblowing cases. This consequently allows for, second, a thorough comparison of cases guided by the framework's various elements.

Third, application of the framework enables a systematic identification of initial and subsequent recipients. Thus, a highly important part of the whistleblowing process can be made more transparent. Closely connected to this is, fourth, the possibility to draw a broader picture of the elements which are particularly relevant with respect to complaint recipients. The assessment and comparison of different individual elements across cases allows for an initial exploration of relations between elements. Consequently, it becomes clear which elements may account for who recipients are, which roles they have, how they respond. All this, in turn, may help to not only answer but also to develop new and various research questions on whistleblowing recipients.

As addressed in the foregoing section, the developed framework may not be able to give precise answers as to how exactly elements are related to the type and timing of recipients' responses. This is arguably due to the not included element of personal attitudes, preferences or knowledge of recipients (e.g. Bjørkelo et al., 2010; Mazerolle \& Brown, 2008; Near \& Miceli, 1995; Smith \& Brown, 2008). A modification of the framework which includes such element may provide further valuable insights. While acknowledging that not having included this element may reduce the framework's explanatory power, it should be kept in mind that "no study can include all variables that may be relevant to whistle-blowing" (Miceli et al., 2012, p. 924). Further, it remains to be seen whether the developed framework can reveal any genuine relations. However, it should be recalled that the framework's purpose is first and foremost to provide initial explorative findings on complaint recipients. In order to enhance the generalizability of findings, a more extensive application of the framework to a larger number of cases is clearly needed.

Concluding, the developed framework is of demonstrated benefit serving as a tool for new and insightful whistleblowing analyses and allowing for a systematic identification and comparison of complaint recipients, their responses, roles and responsibilities. As in the given analysis, the framework can be applied for qualitative in-depth analyses of only one or two cases. However, combining qualitative and quantitative methods by applying the framework to a larger number of ten to twenty cases could be an interesting start for further research and may provide even more insightful findings. Moreover, the overall value of the framework and its elements can only be assessed after having tested it on more cases, presenting different wrongdoings, sectors, industries and countries. Only then, it will become clear whether and how the framework needs modification or refinement. 


\section{Conclusion}

In times where scandals of corporate misconduct are no longer rare, the need to increase transparency on organizations' actions becomes ever more pressing. The process of whistleblowing is here of great relevance. Whistleblowers disclose organizational wrongdoing and thus enable the public to hold private and public organizations accountable (e.g. Lewis et al., 2014, p. 1). Within this process, the people who receive whistleblowers' reports play a decisive role. However, so far only little academic work focuses on the complaint recipient within the whistleblowing process. This study fills this gap by developing and testing a comprehensive analytical framework for exclusively identifying and analysing complaint recipients, their responses, roles and responsibilities.

The framework is applied to two whistleblowing cases from Germany. Preliminary findings suggest that the wrongdoing as well as the proximity or distance between wrongdoer and recipient are decisive for who the initial recipient is and how he responds to the reported wrongdoing. In the given cases, the initial recipients were, on the one hand, an external lawyer, and on the other hand, an internal head of the organization. Neither of them seemed to have role-prescribed responsibilities to respond to the whistleblower's report in a specific manner. This may be related to another main finding, namely that direct corrective action seems to be initiated by subsequent external recipients rather than initial recipients.

While the developed framework proves useful to reconstruct and compare whistleblowing cases from the perspective of the complaint recipient, it moreover allows to increase transparency on these recipients. This is of value not only to the academic debate but also to future whistleblowers and complaint recipients. Yet, this study's findings are limited in their generalizability due to the small number of cases analysed. Subsequently, there is need to apply the developed framework to more and differing cases. Only then it will be possible to draw a comprehensive picture on which elements are relevant with respect to recipients and to consequently evaluate the overall contribution of the framework.

To conclude, this study contributes to existing scholarship by presenting a comprehensive, comparative analytical framework which serves as a tool for systematically analysing complaint recipients within whistleblowing processes. Further testing of this framework may lead to an enriched and deeper understanding of complaint recipients which, in turn, enhances the overall knowledge on the whistleblowing process. 